\title{
Investigating the Effect of Delamination Size, Stacking Sequences and Boundary Conditions on The Vibration Properties of Carbon Fiber Reinforced Polymer Composite
}

\author{
Muhammad Imran ${ }^{a}$, Rafiullah Khan ${ }^{a}$, Saeed Badshah ${ }^{a}$ \\ ${ }^{a}$ Department of Mechanical Engineering, Faculty of Engineering \& Technology, International Islamic \\ University, Islamabad, Pakistan
}

Received: July 07, 2018; Revised: September 28, 2018; Accepted: November 23, 2018

\begin{abstract}
Composite structures are extensively used in various fields ranging from, but not limited to marine, aerospace, automotive, agricultural and industrial equipment due to their unique and excellent properties like weight associated with density. On an increase in their applications, it also requires special attention to manufacture and process the composites to acquire the high level of stability. Most critical defect in composite structures that have attracted many researchers is delamination. Delamination in composite structures are inevitable during service period. Present work is focused on investigating the effect of presence of delamination in the carbon fiber reinforced composite plate using finite element solver software, ANSYS. Present analysis will focus to find the effect of delamination size, boundary constraints and layups on the natural frequency of carbon fiber composite plate. Analytical results were also analyzed using MATLAB environment. Governing equations were derived using Rayleigh-Ritz method. The natural frequency reduced on an increase in delamination size and it is high in clamped-clamped boundary conditions rather than simply supported constraints. The finite element results are then compared with analytical results for clamped-clamped boundary conditions and found in close agreement.
\end{abstract}

Keywords: Finite element analysis, MATLAB solver, composite material, natural frequency, carbon fiber reinforced polymer.

\section{Introduction}

The use of composite materials have rapidly increased in structural applications due to their excellent fatigue properties, high strength to weight ratios, corrosion resistance, impact load-bearing and better wear resistance ${ }^{1,2}$. In addition to their strength and fatigue characteristics, composites are easily controlled by their stacking sequences and fibers ${ }^{3}$. The most common available form in which composites are used in different structural applications is called laminate.

Fiber reinforced polymer composites have been in service since many decades but in recent years its usage has increased rapidly in various industries like construction, automotive, marine and aerospace. Along with its hugely consumption, it also has lot of material and practical issues that needs to be addressed ${ }^{4}$. Although, fiber reinforced polymer composites due to their excellent mechanical properties and less weight parameters, have become an attractive material for many industries like automotive industry but the manufacturing of composite structure itself is a critical task for accurately predicting the best stacking sequences to attain the required mechanical or any other properties ${ }^{5}$.

The applications of carbon-fiber reinforced polymer composite structures have largely increased due to high strength carbon fibers ${ }^{6}$. Cracks or delamination in the laminate of composite structures are unavoidable during the service life

*e-mail: muhammad.imran@iiu.edu.pk of a composite structures ${ }^{7}$. There can be other parameters that also affect the performance of the composites. Moreover cracks in the structure leads to propagation that ultimately leads to the failure of the composite laminate ${ }^{8}$. In composite structure, it has been validated experimentally that presence of crack or delamination affects the performance of the structure due to huge displacements or deformations ${ }^{9}$. Delamination is the internal crack and can cause reduction in structural stiffness that leads to reduced natural frequency ${ }^{10}$. Vibration is the major influencing parameter towards the failure of aerospace, marine and civil structural components ${ }^{11}$. Therefor specific measures should be taken to overcome the effect of vibrations in composite structures. Rapid growth in the applications of carbon fiber reinforced polymer composites, demand for comprehensive testing, design process, testing of structures and structural component is of utmost importance ${ }^{12}$. As a fraction of contribution towards a light weight and high performance composite structures, linear and nonlinear analysis of mode shapes and natural frequencies need to be investigated with great interest.

Pingulkar et al ${ }^{13}$ conducted vibration analysis using finite element software package ANSYS for laminated composite plate. They used glass fiber reinforced polymer and compared their results with results already available in literature. Vo et al ${ }^{14}$ carried out free vibration analysis on composite beams using shear deformation theory under axial loading. They used Hamilton's principle as governing equation. They find the influence of normal strains, stacking 
sequences and poison's ratio on the natural frequency and compared the results with ANSYS and ABAQUS finite element software packages. García-Macías et al ${ }^{15}$ used first order shear deformation to find the free and static vibration analysis in carbon nanotube reinforced skew composite plates. They compared the results with ANSYS package. Tsai et al ${ }^{16}$ carried out free vibration analysis of braided composite plate with hole at the center of the plate using finite element software ANSYS. They analyzed the mode shapes and natural frequencies of the braided composite plate and validated the results from finite element software with the results obtained from experiments and found good agreement. Das and Sarangi ${ }^{17}$ conducted static analysis on functionally graded composite beam. They used ANSYS and solid 186 layered solid element was used as element in ANSYS. Mehar et al ${ }^{18}$ carried out vibration analysis to find the influence of geometrical parameters on the free vibration behavior of FGC nanotube reinforced composite. They used MATLAB tool to solve the governing equations and did simulations infinite element package, ANSYS. Dey et al ${ }^{19}$ analyzed the frequency response of laminated composite plate. They used Mindlin's theory for governing equations and the results were then compared with ANSYS. Braun et al ${ }^{20}$ developed topology optimization algorithm using Matlab and finite element software package Abaqus. They compared the results with available literature. Kumar et al ${ }^{21}$ carried out modal analysis to assess the behavior of smart cantilever composite beam using ANSYS. Modal frequencies and mode shapes were analyzed. Mohammed et $\mathrm{al}^{22}$ carried out vibration analysis of cantilever composite beam produced by hand-lay-up method. They used Matlab, Solidworks and did experiments to find the effect of fiber angles on the mode shapes and natural frequencies. Mallik and Rao ${ }^{23}$ carried out investigations on the vibration of composite beams with and without piezoelectric patches using ANSYS. ${ }^{24}$ conducted finite element and experimental analysis of cracked composite beam. They concluded that frequency value decreased in presence of crack. Shukla and Harsha ${ }^{25}$ did vibration response analysis of turbine blade subjected to crack in the root. They used finite element analysis software ANSYS for modeling of crack and simulations. Yurddaskal et al ${ }^{26}$ studied numerical and experimental analysis to find the effect of foam properties on vibration response of curved sandwich composite panels. Sandwich panels were analyzed using ANSYS for clamped square composite panels. Natural frequencies increased with increase in foam density and curvature. Juhász et al ${ }^{27}$ developed a model using finite element analysis predicting the modal analysis in through-width delaminated composite plate and the results were validated experimentally. Hirwani et al ${ }^{28}$ carried out investigations to find the effect of delamination on the vibration characteristics of spherical structure, cylindrical structure, elliptical structure, hyperboloid structure and flat structures of laminated curved composites. Higher order shear deformation theory was used to develop analytical model. Finite element software ANSYS was used for simulation and to fetch natural frequencies. Sadeghpour et al ${ }^{29}$ carried out free vibration analysis of debonded curved sandwich beam using Lagrange's principle and the Rayleigh-Ritz method as base for governing equations. Simulations were done by using finite element analysis software ANSYS Workbench. They concluded that curved and flat debonded composite beam had similar vibration response. Zhang et al ${ }^{30}$ conducted finite element and experimental analysis to find the vibration properties of carbon fiber and glass fiber reinforced polymer composite plates. They analyzed the effect of delamination size and location on the natural frequencies. Hirwani et al ${ }^{31}$ carried out experiments to find the delamination effect on woven glass/epoxy composite plate. Then the results were compared with finite element simulation software ANSYS. Shrigandhi et al ${ }^{32}$ conducted modal analysis of composite sandwich panels using finite element analysis. Hwu et al ${ }^{33}$ carried out free vibration characteristics of composite sandwich plates and cylindrical shells. Modified first-order-sheardeformation theory was used for analytical analysis. Lee et al ${ }^{34}$ conducted numerical analysis to find the effect of fiber orientation on the rectangular carbon fiber reinforced polymer composite plate. The numerical results were then compared with the commercial finite element software.

The review of the above work shows that there is not much work has been carried out to find vibration behavior of carbon fiber reinforced polymer composite structures using finite element software packages. Also analytical approaches to solve mode shapes and natural frequency are rare. The literature having finite element analysis using these tools to find the natural frequencies for carbon fiber reinforced polymer is very poor. Therefore in the present study, carbon fiber reinforced polymer composite with and without delamination is investigated. The effect of delamination size in the middle of the plate, ply orientation in laminate sheets and boundary conditions to fetch mode shapes and natural frequency are studied extensively.

\section{Finite Element Approach}

In order to model a pre-delaminated area, only the nodes in contact with each other (laminated) were merged. The other nodes (delaminated) were left un-merged in order to simulate the delamination of the plate. Figure 1 depicts the region between layer four and five containing nodes that were left un-merged.

This methodology is consistent with methods for presimulation delamination and damage that are used in the industry. Because the delamination region was not bonded in any way, a cohesive zone model, or virtual crack closure technique was not necessary. Mapping the mesh between laminated layers and the delaminated layers was difficult using quadrilateral elements; therefore triangular elements 
were used for the layers containing the delaminated region. Figure 2 depicts the triangular mesh used for layers four and five.

For FEM analysis of the composite plate specified, ANSYS APDL was used for modelling, preprocessing, meshing, and solving. In ANSYS, it is not possible to easily simulate pre-delaminated regions using shell elements. For this composite plate, the thickness to length ratio is just over $10 \%$, so it is questionable whether or not shell elements will capture the true behavior of the composite. For this simulation, solid elements were used with one element in the thickness direction for each prepeg layer. In order to properly simulate the fiber orientation for each laminate layer, custom coordinate systems were specified for each layer corresponding to the fiber orientation needed. For the simply supported constraint case, the bottom edges of the plate were constrained to have zero displacement in all cartesian axes.

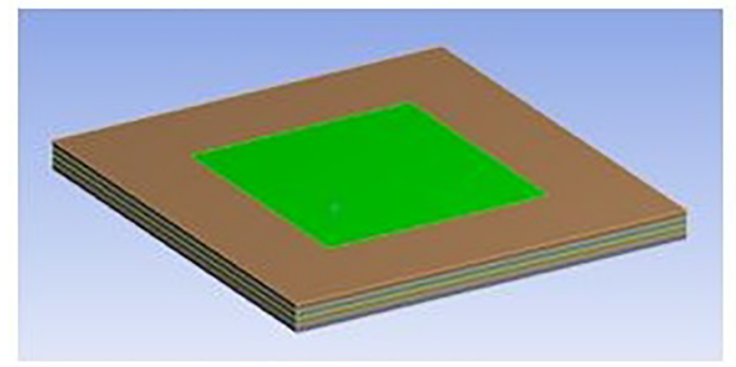

Figure 1. Schematic diagram of delaminated region, $56.25 \%$

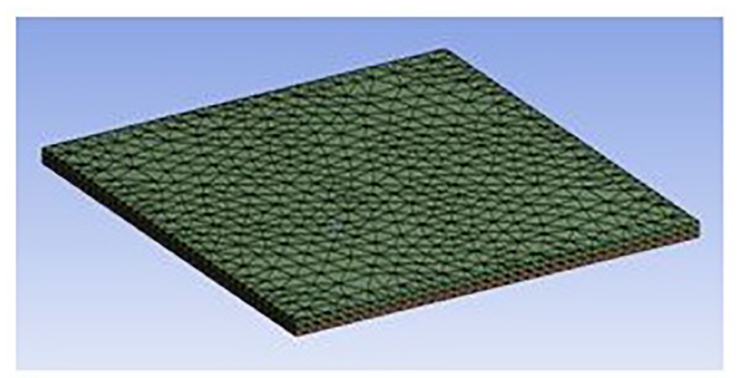

Figure 2. Triangular mesh, layers four and five

\section{Analytical Approach}

The differential equation for the transverse bending of a plate having rectangular orthotropic plate is depicted in equation 1

$D_{x} \frac{\partial^{4} \omega}{\partial x^{4}}+2 D_{x y} \frac{\partial^{4} \omega}{\partial x^{2} \partial y^{2}}+D_{y} \frac{\partial^{4} \omega}{\partial y^{4}}+\rho \frac{\partial^{2}}{\partial t^{2}}=0$

Where $D_{x}, D_{y}, D_{x y}$ are the stiffness terms computed for homogenous plate. Because they are computed for such a plate, we must change them with the terms which describe a laminate composite plate.
The terms $\mathrm{D}_{11}, \mathrm{D}_{12}$, and $\mathrm{D}_{66}$ are computed using the equations presented below.

$$
\begin{gathered}
D_{11}=\frac{E_{x} h^{3}}{12\left(1-v_{x y} v_{y x}\right)} \\
D_{12}=D_{21}=\frac{v_{y x} E_{x} h^{3}}{12\left(1-v_{x y} v_{y x}\right)}=\frac{v_{x y} E_{y} h^{3}}{12\left(1-v_{x y} v_{y x}\right)} \\
D_{22}=\frac{E_{y} h^{3}}{12\left(1-v_{x y} v_{y x}\right)} \\
D_{66}=\frac{G_{x y} h^{3}}{6}
\end{gathered}
$$

The moment curvature relations are used for governing equations;

$$
\begin{gathered}
M_{x}=-D_{x}\left(\frac{\partial^{2} \omega}{\partial x^{2}}+v_{y} \frac{\partial^{2} \omega}{\partial y^{2}}\right) \\
M_{y}=-D_{y}\left(\frac{\partial^{2} \omega}{\partial y^{2}}+v_{x} \frac{\partial^{2} \omega}{\partial x^{2}}\right) \\
M_{x y}=-2 D_{x} \frac{\partial^{2} \omega}{\partial_{x} \partial_{y}}
\end{gathered}
$$

From the above equations, Rayleigh Ritz method is used to find the frequencies as in equation 9

$$
\omega^{2}=\frac{1}{\rho}\left(\frac{A^{4} D_{x}}{a^{4}}+\frac{B^{4} D_{y}}{b^{4}}+\frac{2 C D_{x y}}{a^{2} b^{2}}\right)
$$

Where A, B, C and D are frequency coefficients and depends upon the boundary conditions applied and are determined from the equations $10 \& 11$ in case of simply supported plate

$$
\begin{aligned}
& A=\gamma_{0} \\
& B=\epsilon_{0}
\end{aligned}
$$

After putting the value of all sides clamped boundary conditions in the equation ${ }^{9}$, we will solve this in Matlab tool to fetch the frequencies.

By using moment curvature relationship, we find.

$W_{m n}=A_{m n} \sin \frac{m \pi x}{a} \sin \frac{n \pi x}{b}$ where $A_{m n}$ is an amplitude coefficient depends on the initial conditions and $m$ and $n$ are integers. Substituting the $W_{m n}$ equation into simple harmonic equations gives the final equation

$$
\omega_{m, n}=\frac{\pi^{2}}{a^{2} \sqrt{\rho}} \sqrt{\begin{array}{l}
D_{x} m^{4}+2 D_{x, y} m^{2} n^{2}\left(\frac{a}{b}\right)^{2} \\
+D_{y} n^{4}\left(\frac{a}{b}\right)^{4}
\end{array}}
$$


Where, $a, b$ and $\rho$ are width of the plate, height of the plate and density respectively.

\section{Results and Discussions}

In this section, the effects of stacking sequence, boundary condition, and delaminated area on the natural frequency of each mode number will be discussed. Tables and figures from the previous section will be referred to regarding notable trends and patterns in the data. Maximum overall modal frequencies occurred for the simply supported boundary cases across all plates, followed by free on all edges, cantilever supported, and clamped on all edges.

\section{Effect of Delaminated Area}

For the most part, across all boundary conditions and stacking sequences, the deviation of frequencies from $0 \%$ to $56.25 \%$ delamination is minimal. The greatest deviation of frequencies occurs for the clamped boundary condition on all stacking sequences. The $0 \%, 6.25 \%$, and $25 \%$ delamination conditions do not deviate very far from each other, whereas the $56.25 \%$ delamination condition experiences significant deviation from the others at modes 5, 7, 9, and 12 as shown in Figure 3 and Figure 4. The following table will attempt to investigate the difference between modes 5, 7, 9, and 12 for the $0 / 90 / 45 / 90$ stacking sequence under the clamped edges boundary condition.

It is clear that the delamination area has significantly impacted both the shapes of the modes, and the natural frequencies that the modes occur at.

For the 5, 7, and 9 mode shapes, the deviation from $0 \%$ in shape is minimal, with the delaminated region affecting the maximum deformation and placement of the maximum deformation. For the 12 th mode shape, the results are completely different than the $0 \%$ delamination condition. We

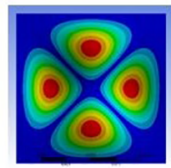

(a)

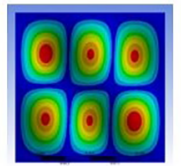

(b)

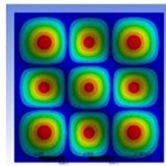

(c)

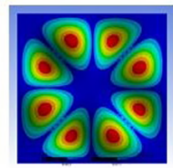

(d)
Figure 3. Mode shapes for $(0 / 90 / 45 / 90)$ sequence with $0 \%$ delamination a) for mode 5, b) for mode 7, c) for mode 9 and d) for mode 12 .

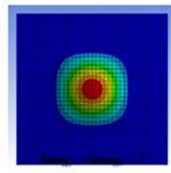

(a)

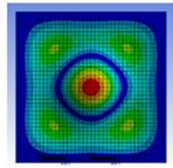

(b)

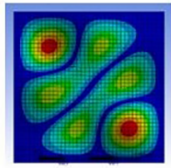

(c)

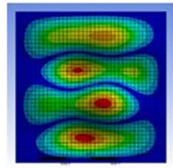

(d)
Figure 4. Mode shapes for 0/90/45/90 with 56.25\% delamination. a) for mode 5, b) for mode 7, c) for mode 9 and d) for mode 12 . can conclude that the size of the delaminated region heavily impacts the shape of the modes if not the frequencies as well.

\section{Effect of Boundary Conditions}

Because the mode shapes for different boundary conditions are completely different, comparing them is not of significant value. Instead we can comment on the trend of natural frequencies in the different boundary conditions.

\section{Clamped on All Edges}

For the fully clamped boundary condition, we can see that the general trend in natural frequencies is linear, starting at around $1500 \mathrm{~Hz}$ and increasing to around $5900 \mathrm{~Hz}$ at mode 12. As aforementioned, the greatest deviations in modal frequencies occured for the plate with $56.25 \%$ delamination, and this was true across all stacking sequences.

\section{Free on All Edges}

For the freely supported boundary conditions, it is consistent with theory that the first six modal frequencies are zero. With anybody in any three dimensional environment, there are six associated degrees of freedom. Because the first six modes of vibration are purely one of the six degrees, it is consistent that the first six modes of vibration have zero frequency. For the remaining modes, there is an increase in frequency with decreasing rate up to mode 11 with a spike in frequency for mode 12 . In fact, this spike in modal frequency is greater than any other increase in frequency on average, with an average increase of about $500 \mathrm{~Hz}$ for every plate stacking sequence.

\section{Simply supported}

For the simply supported cases, there is a similar effect occurring as with the freely supported case. This time, however, three of the six degrees of freedom are being constrained: translation on all axes. While the roller supports are not being constrained directionally, the pin support restricts the motion of the structure in the three translational axes. Therefore, it can be seen that the first three modes of vibration are zero for these cases. Across all stacking sequences, the modal frequencies are seen to increase from around $1000 \mathrm{~Hz}$ at mode 4 to just about $7500 \mathrm{~Hz}$ for mode 12. Additionally, for these cases there seems to be some significant deviation in modal frequencies for the different delamination conditions. For instance, the 0/90/45/90 modal frequencies show deviation from $0 \%$ for the $56.25 \%$ delamination case especially. For $0 / 45$ and $0 / 90$, the modal frequencies for all of the delamination conditions are much tighter in distribution. 


\section{Cantilever Supported}

Of all of the boundary conditions, cantilever supported exhibits the tightest distribution of modal frequencies across all of the stacking sequences and delamination conditions. Generally, the maximum modal frequency occurs at 2500 $\mathrm{Hz}$, and minimum at about $90 \mathrm{~Hz}$. The trend of increase between these two bounds varies across the stacking sequences, but general trend is linear. It is safe to conclude that, due to these trends, the effect of the delaminated area on the modal frequencies is not as powerful as it was for any of the other boundary conditions. Additionally, instead of maximum deflection occurring at interior regions of the plate, maximum deflection for this boundary condition generally occurs at the freely supported edge of the plate (opposite of clamped edge).

\section{Effect of Stacking Sequences}

To investigate the effect of the stacking sequences, we can observe the first 12 mode shapes for each. The following table shows the mode shapes with respect to the stacking sequences for the $0 \%$ delaminated, clamped on all edges.

Because each laminate later behaves as an orthotropic material, changing the fiber orientation for each layer effectively makes the material anisotropic, with varying properties according to the stacking sequence used. The most notable differences in mode shape seem to occur at modes $7,8,9,10$, and 11 with the others being very closely related if not exactly the same on comparison of Figure 5 and Figure 6. For mode shapes 7, 8, and 9, the mode shapes for $0 / 90 / 45 / 90$ and $0 / 90$ are very closely related. This is most likely due to the fact that, because the directional young's moduli for the prepeg are equal, orienting the fiber at 90 degrees does not change the material behavior.

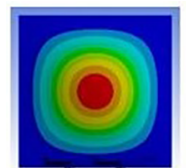

Mode 1

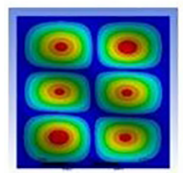

Mode 5

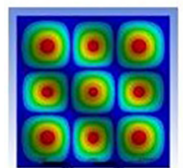

Mode 9

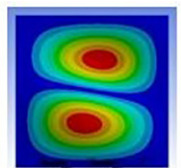

Mode 2

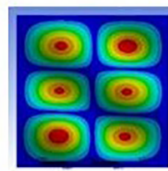

Mode 6

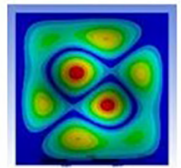

Mode 10

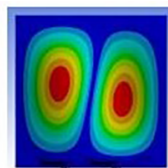

Mode 3

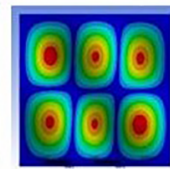

Mode 7

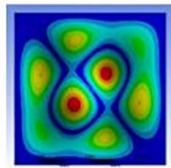

Mode 11

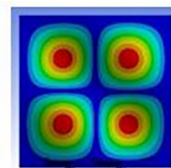

Mode 4

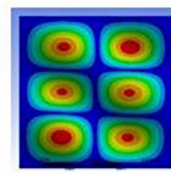

Mode 8

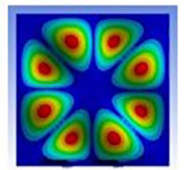

Mode 12
Figure 5. Mode shapes with respect to the 0/90/45/90 stacking sequence for the $0 \%$ delaminated region

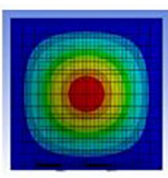

Mode 1

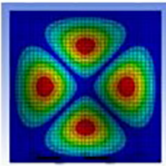

Mode 5

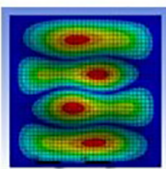

Mode 9

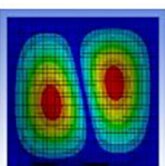

Mode 2

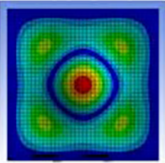

Mode 6

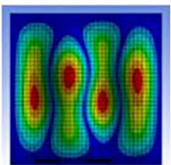

Mode 10

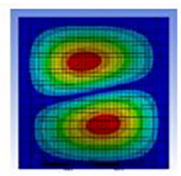

Mode 3

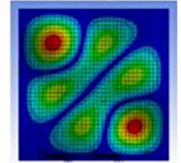

Mode 7

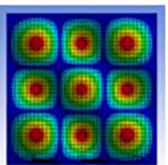

Mode 11

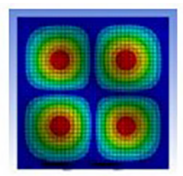

Mode 4

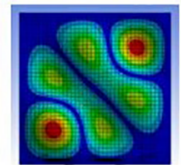

Mode 8

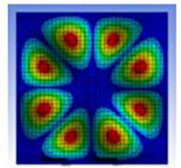

Mode 12
Figure 6. Mode shapes with respect to the $0 / 45$ stacking sequences for the $0 \%$ delaminated region

The results obtained from Rayleigh-Ritz method were then compared with the results obtained from ANSYS software package and were in good agreement as shown in Table 1. Percentage error was lowest for lower modes and maximum error was observed in mode 5 rather than mode 6 surprisingly. Table 1 indicates that for mode 1, highest frequency is observed in 0/90 layup for all sides clamped boundary conditions and lowest value of natural frequency is observed for the case of $0 / 45$ stacking sequence. For higher mode $^{(\text {mode })}$, same pattern is observed. It may be further noted that the analytical results have higher values than the finite element results for all three stacking sequences discussed for all sides clamped boundary condition.

On the comparison of results for higher modes ${ }^{7-12}$, Mode 7 has the lowest percentage error as compared to mode 12 in 0/90/45/90 stacking sequences as shown in Table 2. On contrary to $0 / 90 / 45 / 90,0 / 45$ and $0 / 90$ sequences showed an increase in percentage error on an increase in modes. Trend of increase in natural frequencies for higher modes (mode 7-12) is similar to trend of lower modes (mode 1-6). Furthermore, as we move from lowest to highest modes, percentage error between the results of finite element and analytical method tend to increase and maximum error percentage $3.8 \%$ is observed for the stacking sequence of $0 / 45$ lay-up. This error is negligible and does not affect much to predict the behavior of carbon fiber reinforced polymer composite plate.

\section{Conclusion}

Therefore, the $0 / 90 / 45 / 90$ sequence only deviates from the material properties of the $0 / 90$ in that two layers of eight are oriented at 45 degrees. Modes 7 and up are elastic modes, and the direction of waves in the material for these two stacking 
Table 1. First six natural frequencies for stacking sequences $0 / 90 / 45 / 90,0 / 45$ and $0 / 90$

\begin{tabular}{|c|c|c|c|c|c|c|c|c|}
\hline $\begin{array}{l}\text { Boundary } \\
\text { condition }\end{array}$ & $\begin{array}{c}\text { Stacking } \\
\text { Sequences }\end{array}$ & Method & Mode 1 & Mode 2 & Mode 3 & Mode 4 & Mode 5 & Mode 6 \\
\hline \multirow{9}{*}{$\mathrm{CCCC}$} & \multirow{3}{*}{$0 / 90 / 45 / 90$} & FEA, Hz & 879.65 & 1795.6 & 1795.6 & 2547.6 & 3245.7 & 3259.1 \\
\hline & & $\begin{array}{c}\text { Analytical, } \\
\mathrm{Hz}\end{array}$ & 886.7904 & 1822.9 & 1822.9 & 2522.2 & 3402.3 & 3402.3 \\
\hline & & Error \% & 0.8 & 1.5 & 1.5 & -1.0 & 4.6 & 4.2 \\
\hline & \multirow{3}{*}{$0 / 45$} & FEA, Hz & 873.84 & 1773.3 & 1773.3 & 2602.5 & 3156.9 & 3173.1 \\
\hline & & $\begin{array}{c}\text { Analytical, } \\
\mathrm{Hz}\end{array}$ & 882.4113 & 1802 & 1802 & 2659.03 & 3237.7 & 3237.7 \\
\hline & & Error \% & 1.0 & 1.6 & 1.6 & 2.1 & 2.5 & 2.0 \\
\hline & \multirow{3}{*}{$0 / 90$} & FEA, $\mathrm{Hz}$ & 884.65 & 1815.7 & 1815.7 & 2487.6 & 3331.2 & 3339.1 \\
\hline & & $\begin{array}{c}\text { Analytical, } \\
\mathrm{Hz}\end{array}$ & 889.7742 & 1837.03 & 1837.03 & 2522.2 & 3386 & 3402.3 \\
\hline & & Error \% & 0.6 & 1.2 & 1.2 & 1.4 & 1.5 & 1.9 \\
\hline
\end{tabular}

Table 2. Natural frequencies (7-12 modes) for stacking sequences $0 / 90 / 45 / 90,0 / 45$ and $0 / 90$

\begin{tabular}{|c|c|c|c|c|c|c|c|c|}
\hline $\begin{array}{l}\text { Boundary } \\
\text { condition }\end{array}$ & $\begin{array}{c}\text { Stacking } \\
\text { Sequences }\end{array}$ & Method & Mode 7 & Mode 8 & Mode 9 & Mode 10 & Mode 11 & Mode 12 \\
\hline & & FEA & 3883.8 & 3883.8 & 5060.5 & 5190.5 & 5190.5 & 5737.9 \\
\hline & $0 / 90 / 45 / 90$ & Analytical & 3898.3 & 3898.3 & 5100 & 5528.2 & 5528.2 & 5920.5 \\
\hline & & Error \% & 0.4 & 0.4 & 1.6 & 6.1 & 6.1 & 3.1 \\
\hline & & FEA & 3942.3 & 3942.3 & 5008.5 & 5008.5 & 5224.1 & 5736.3 \\
\hline \multirow[t]{5}{*}{$\mathrm{CCCC}$} & $0 / 45$ & Analytical & 4054.1 & 4054.1 & 5165.02 & 5165.02 & 5398.9 & 5962.7 \\
\hline & & Error \% & 2.8 & 2.8 & 3.0 & 3.0 & 3.2 & 3.8 \\
\hline & & FEA & 3819.3 & 3819.3 & 4885.4 & 5363.7 & 5363.7 & 5735.9 \\
\hline & $0 / 90$ & Analytical & 3898.3 & 3898.3 & 5002.9 & 5528.2 & 5528.2 & 5920.5 \\
\hline & & Error \% & 2.0 & 2.0 & 2.3 & 3.0 & 3.0 & 3.1 \\
\hline
\end{tabular}

sequences must be identical in that they are not accounting for the 45 degree oriented layers of the 0/90/45/90 plate, thus making the mode shapes identical. The most interesting mode shapes are 10 and 11 , where each stacking sequence exhibits a shape that is unique to its stacking sequence. In fact, through all of the stacking sequences there are shared mode shapes except for mode 11 . We can conclude that the stacking sequence has an impact on the mode shape for only some of the modes of vibration. It was also concluded that the free edge of the plate experiences the maximum deflection for almost every single mode. This is expected for cantilever supported beams, where the opportunity for deflection is greatest at the end of the beam.

\section{References}

1. Balakrishnan P, John MJ, Pothen L, Sreekala M, Thomas S. Natural fibre and polymer matrix composites and their applications in aerospace engineering. In: Rana S, Fangueiro R, eds. Advanced Composite Materials For Aerospace Engineering: Processing, Properties and Applications. Cambridge: Woodhead Publishing; 2016. p. 365-583.
2. Imran M, Khan R, Badshah S. Finite Element Analysis to Investigate the Influence of Delamination Size, Stacking Sequence and Boundary Conditions on the Vibration Behavior of Composite Plate. Iranian Journal of Materials Science \& Engineering. 2018. In press.

3. Agarwal BD, Broutman LJ, Chandrashekhara K. Analysis and Performance of Fiber Composites. Hoboken: John Wiley \& Sons; 2017.

4. Agarwal K, Kuchipudi SK, Girard B, Houser M. Mechanical properties of fiber reinforced polymer composites: A comparative study of conventional and additive manufacturing methods. Journal of Composite Materials. 2018;52(23):3173-3181.

5. Tseng HC, Chang RY, Hsu CH. Numerical prediction of fiber orientation and mechanical performance for short/long glass and carbon fiber-reinforced composites. Composites Science and Technology. 2017;144:51-56.

6. Imran M. Pre-stress and Free Vibration Optimization of Composite Ocean Current Turbine Blade. International Journal of Science, Engineering and Innovative Research. 2015;3:5-8.

7. Imran M, Rafiullah K, Badshah S. Vibration Analysis of Cracked Composite Laminated Plate and Beam Structures. Romanian Journal of Acoustics and Vibration. 2018;15(1):313. 
8. Imran M, Rafiullah K, Saeed Badshah. Vibration Analysis of Cracked Composite Laminated Plate. Pakistan Journal of Scientific and Industrial Research Series A: Physical Sciences. 2018;61(2):84-90.

9. Zhang H, Sfarra S, Sarasini F, Ibarra-Castanedo C, Perilli $\mathrm{S}$, Fernandes H, et al. Optical and Mechanical Excitation Thermography for Impact Response in Basalt-Carbon Hybrid Fiber-Reinforced Composite Laminates. IEEE Transactions on Industrial Informatics. 2018;14(2):514-522.

10. Zhang Z, Shankar K, Morozov EV, Tahtali M. Vibration-based delamination detection in composite beams through frequency changes. Journal of Vibration and Control. 2016;22(2):496-512.

11. Garcia C, Trendafilova I, Zucchelli A, Contreras J. The effect of nylon nanofibers on the dynamic behaviour and the delamination resistance of GFRP composites. MATEC Web of Conferences. 2018;148:14001.

12. Imran M, Khan R, Badshah S. A Review on the Effect of Delamination on the Performance of Composite Plate. Pakistan Journal of Scientific and Industrial Research Series A: Physical Sciences. 2018;61(3):173.

13. Pingulkar P, Suresha B. Free Vibration Analysis of Laminated Composite Plates Using Finite Element Method. Polymers \& Polymer Composites. 2016;24(7):529-538.

14. Vo TP, Thai HT, Aydogdu M. Free vibration of axially loaded composite beams using a four-unknown shear and normal deformation theory. Composite Structures. 2017;178:406-414.

15. García-Macías E, Castro-Triguero R, Saavedra Flores EI, Friswell MI, Gallego R. Static and free vibration analysis of functionally graded carbon nanotube reinforced skew plates. Composite Structures. 2016;140:473-90.

16. Tsai KH, Hwan CL, Lin MJ, Lo CC, Hwang JL. Free Vibration of Braided Composite Plates with a Center Hole. China Mechanical Engineering Journal. 2017;38(2):135-144.

17. Das S, Sarangi S. Static Analysis of Functionally Graded Composite Beams. IOP Conference Series: Materials Science and Engineering. 2016;149:012138.

18. Mehar K, Panda SK, Dehengia A, Kar VR. Vibration analysis of functionally graded carbon nanotube reinforced composite plate in thermal environment. Journal of Sandwich Structures \& Materials. 2016;18(2):151-173.

19. Dey S, Mukhopadhyay T, Spickenheuer A, Adhikari S, Heinrich G. Bottom up surrogate based approach for stochastic frequency response analysis of laminated composite plates. Composite Structures. 2016;140:712-27.

20. Braun M, Villa EI, Riojas-Roldán H, Rocco CG. A topological optimization algorithm applied to the design of composites patch repair of mixed-mode cracked plate. Journal of Composite Materials. 2017;52(17):2387-2395.
21. Yashavantha Kumar GA, Sathish Kumar KM. Free vibration analysis of smart composite beam. Materials Today: Proceedings. 2017;4(2 Pt A):2487-2491.

22. Mohammed D. Effect of Fiber Angles on Dynamic Response of Cantilever Composite Beams. ZANCO Journal of Pure and Applied Sciences. 2017;29(1):157-163.

23. Mallik PKS, Rao DS. Vibration control on composite beams with multiple piezoelectric patches using finite element analysis. International Research Journal of Engineering and Technology. 2017;7(4):906-911.

24. Jadhav V, Bhoomkar MM. Experimental and Numerical FEM Analysis of Cracked Composite Cantilever Beam by Vibration Techniques. International Journal of Engineering Science. 2016;6(4):3347-3351.

25. Shukla A, Harsha SP. Vibration Response Analysis of Last Stage LP Turbine Blades for Variable Size of Crack in Root. Procedia Technology. 2016;23:232-239.

26. Yurddaskal M, Ozmen U, Kir M, Okutan Baba B. The effect of foam properties on vibration response of curved sandwich composite panels. Composite Structures. 2018;183:278-285.

27. Juhász Z, Turcsán T, Tóth TB, Szekrényes A. Sensitivity analysis for frequency based prediction of crack size in composite plates with through-the-width delamination. International Journal of Damage Mechanics. 2018;27(6):859-876.

28. Hirwani CK, Patil RK, Panda SK, Mahapatra SS, Mandal SK, Srivastava L, et al. Experimental and numerical analysis of free vibration of delaminated curved panel. Aerospace Science and Technology. 2016;54:353-370.

29. Sadeghpour E, Sadighi M, Ohadi A. Free vibration analysis of a debonded curved sandwich beam. European Journal of Mechanics - A/Solids. 2016;57:71-84.

30. Zhang Z, He M, Liu A, Singh HK, Ramakrishnan KR, Hui D, et al. Vibration-based assessment of delaminations in FRP composite plates. Composites Part B: Engineering. 2018;144:254-266.

31. Hirwani CK, Sahoo SS, Panda SK. Effect of delamination on vibration behaviour of woven Glass/Epoxy composite plate-An experimental study. IOP Conference Series: Materials Science and Engineering. 2016;115(1):012010.

32. Deshmukh PV, Shrigandhi GD. Modal Analysis of Composite Sandwich Panel. International Journal of Innovations in Engineering Research And Technology. 2015;2(10):1-7.

33. Hwu C, Hsu HW, Lin YH. Free vibration of composite sandwich plates and cylindrical shells. Composite Structures. 2017; 171:528-537.

34. Lee SK, Kim MW, Park CJ, Chol MJ, Kim G, Cho JM, et al. Effect of fiber orientation on acoustic and vibration response of a carbon fiber/epoxy composite plate: Natural vibration mode and sound radiation. International Journal of Mechanical Sciences. 2016;117:162-173. 